Article available at nttp://WwW.parasite-journal.org or nttp://ax.dol.org/10.1051/parasite/2002092143

\title{
SCHISTOSOMA MANSONI: KINETICS OF GLOMERULONEPHRITIS IN MONGOLIAN GERBILS AND ITS CORRELATION WITH INTENSITY AND DURATION OF INFECTION
}

\author{
CHISTY M.M.*, NARGIS M.*, SATO H.*, INABA T.*, TAKAHASHI G.** \& KAMIYA H.*
}

\section{Summary :}

The frequent occurrence of glomerular lesions in schistosomiasis patients has been reported, although appropriate animal models for the study of schistosomal glomerulonephritis have not been developed. To analyze the relationship between glomerulonephritis and Schistosoma mansoni infection, gerbils, Meriones

unguiculatus, were infected with different number of cercariae and sacrificed at different weeks of post infection. Fifty cercariae were the optimum dose to produce the disease, glomerulonephritis, without early death of the animal. Infected gerbils showed heterogeneous types of glomerular lesions with increased serum creatinine level. Immune complex deposition was not detected at glomeruli of infected gerbils even by means of immunuofluorescence and also by transmission electron microscopy. However, infiltration of mononuclear cells in and around some of the altered glomeruli was observed.

Immunohistochemical staining, using monoclonal antibody (HUSMM.g. 15) specific to gerbil's T-cells, revealed significant infiltration of T-cells. These findings suggest that T-cells might be involved in the development of glomerulonephritis. Gerbil could be a useful model to clarify the role of T-cells in the development of glomerulonephritis of schistosomiasis.

KEY WORDS : glomerulonephritis, Schistosoma mansoni, Mongolian gerbils, T-cells, immunohistochemistry.
Résumé : SCHISTOSOMA MANSONI : DÉVELOPPEMENT D'UNE GLOMÉRULONÉPHRITE CHEZ LA GERBILLE DE MONGOLIE ET CORRÉLATION AVEC L'INTENSITÉ ET LA DURÉE DE L'INFECTION

Les lésions glomérulaires des patients atteints de schistosomiase ont été souvent rapportées, cependant, il n'a pas été développé de modèle animal permettant d'étudier les lésions de glomérulonéphrites. Afin d'analyser les relations entre glomérulonéphrite et infection à Schistosoma mansoni, des gerbilles, Meriones unguiculatus, ont été infectées avec des quantités variables de cercaires et sacrifiées à des dates différentes après cette infestation. 50 cercaires sont la quantité optimale pour provoquer une glomérulonéphrite sans entraîner la mort de l'animal. Les gerbilles infectées montrent des lésions glomérulaires hétérogènes avec une élévation de la créatinine sérique. II n'a pas été observé de dépots de complexes immuns au niveau des glomérules, ni en immunofluorescence, ni en microscopie électronique à transmission. Cependant, un infiltrat de cellules mononuclées dans et autour certains glomérules a été observé. Une étude immunohistochimique, utilisant un anticorps monoclonal (HUSM-M.g. 15) spécifique de cellules T de gerbilles, a révélé une infiltration de ces cellules. Cette découverte suggère que les cellules $T$ pourraient intervenir dans le développement de la glomérulonéphrite. Les gerbilles pourraient être un bon modèle afin de clarifier le rôle des cellules T dans le développement des glomérulonéphrites schistosomiennes.

MOTS CLÉS : glomérulonéphrite, Schistosoma mansoni, gerbille, cellules T immunohistochimie.

from 15 to $40 \%$ (Andrade et al., 1971; Rocha et al., 1976). It was thought that schistosomal glomerulonephritis might be a typical example of immune complex (IC) glomerulonephritis (GN) because of their presence of schistosomal worm antigen (De Brito et al., 1998) and IC in the glomeruli (Sobh et al., 1991). However, treatment did not show any improvement rather progression to chronic renal failure (Sobh et al., 1988), and polyclonal B-cells activation alone was not enough to induce GN in mice (Fujiwara et al., 1988). Thus besides IC, host related factors, such as T-cells or macrophage function, seem to be involved (Van Velthuysen, 1996). Several laboratory animal species from mouse to chimpanzee have been used for the study of $S$. mansoni infection (De Brito et al., 1971; Brack et al., 1972; Andrade \& Susin, 1974; Sobh et al., 1991). However as a model of the disease, none of these hosts was considered as ideal. For example, the lesions in chimpanzees closely resemble those in humans (Sadun et al., 1975),

\footnotetext{
* Department of Parasitology, ${ }^{* *}$ Second Department of Anatomy, Hirosaki University School of Medicine, Hirosaki 036-8562, Aomori, Japan. Correspondence: H. Kamiya.

Tel.: +81-172-39-5043 - Fax: +81-172-39-5045.

E-mail: hkamiya@cc.hirosaki-u.ac.jp
} 
but these animals are not widely accepted to use for animal experiments. On the other hand, hamsters and mice spontaneously develop renal pathology with age (Robinson et al., 1982). An animal model should provide a normal worm development and the lesions comparable to those of human. In addition, it should be easily maintained. Worm development and liver lesions recorded in gerbils infected with $S$. japonicum more closely resembled to those of humans than did the lesions observed in mice or rabbits (Yingrui et al., 1983). But the literature does not contain any information regarding schistosomal glomerulonephritis in gerbils.

The objective of this experiment was to study the glomerulonephritis in gerbils infected with $S$. mansoni and its correlation with intensity and duration of infection.

\section{MATERIALS AND METHODS}

\section{PARASITES}

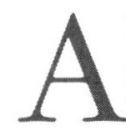

Puerto Rican strain of Schistosoma mansoni maintained in Biomphalaria glabrata snails and Mongolian gerbils, Meriones unguiculatus, was used through out the experiments. Cercariae were used within one hour of being shed.

\section{ANIMALS}

In the present study 180 gerbils, 6-8 weeks old of either sex were used. Among these, 144 were infected with different doses of cercariae (25, 50, 100 and 150 cercariae) of $S$. mansoni and the remaining 36 animals served as controls. These animals were bred at the Institute for Animal Experiments of our university. Animals were fed food pellets and water ad libitum. All animal experiments were performed according to the Guidelines on Animal Experimentation as set out by Hirosaki University.

\section{INFECTIONS}

The animals were anaesthetized by intraperitoneal injection of $30 \mathrm{mg} / \mathrm{kg} \mathrm{Nembutal}{ }^{\circledR}$ (Pentobarbital sodium; Abbot Laboratories, North Chicago, USA). The infections with cercariae were carried out by the ring method of Smithers and Terry (1965). The mean number of cercariae used in each animal was calculated from six random aliquots of the cercarial suspension. For cercarial penetration, one-hour was allowed after which the water in the ring was examined for nonpenetrating cercariae.

\section{LABORATORY EVALUATIONS}

S. mansoni infected gerbils and controls matched for age and sex were subjected to the following measurements: 1) Serum creatinine concentration $(\mathrm{mg} / \mathrm{dl})$; 2) blood urea nitrogen (BUN) concentration $(\mathrm{mg} / \mathrm{dl})$;
3) Serum albumin, globulin and total protein concentration $(\mathrm{mg} / \mathrm{dl})$, and serum cholesterol concentration (mg/dl). Automatic Biochemical Analyzer (Olympus AU 600) was used for biochemical evaluations.

\section{Histopathological EVALUATIONS}

Animals were killed by an anesthetic over dose of ether, at various weeks (wks) post infection (p.i). Kidney tissues of the sacrificed animals were subjected to the following examinations:

\section{A) Light microscopic examination}

All collected kidney samples were fixed in $10 \%$ neutral phosphate buffered formalin, routinely processed, embedded in paraffin, sectioned at $4 \mu \mathrm{m}$ and stained with hematoxylin and eosin (H/E), Periodic Acid Schiff (PAS), Periodic acid silver methanamine (PASM) and Congo red stains. In average, four sections were made from the hilar region of each kidney and were examined microscopically. In each animal, 30 glomeruli were randomly selected from four sections. The mean number of cells per glomerular cross-section (c/gcs) was counted by using high power objectives. The mean glomerular diameter was measured by means of an ocular micrometer. Glomerular abnormalities, especially mesangial cell proliferation, alteration of the mesangial matrix, thickening of the glomerular basement membrane (GBM), hemorrhage and necrosis along with tubulo-interstitial changes were recorded.

\section{B) Transmission Electron Microscopy (TEM)}

TEM was performed in three animals from each group at each time points. Removed kidneys were immediately sliced at $0.5 \mathrm{~mm}$ thickness, and prefixed in cold $2.5 \%$ glutaraldehyde solution in $0.1 \mathrm{M}$ phosphate buffer (PB), $\mathrm{pH} 7.4$, at $4^{\circ} \mathrm{C}$ for more than two hours. They were washed in two changes of cold $\mathrm{PB}$ for $10 \mathrm{~min}$, and post-fixed in cold $1 \%$ osmium tetra-oxide in $\mathrm{PB}$ for two hours. Specimens were then washed in three changes of cold distilled water, stained en block with $1 \%$ uranyl acetate, dehydrated in a series of alcohol, and embedded in epoxy resin. Ultrathin sections were cut, stained with uranyl acetate and lead citrate, and observed with an electron microscope (JEOL, Japan).

\section{C) Immunohistochemical examination}

a) Immunofluorescent microscopy for detection of immune complex-related immunoglobulins (IgG, IgM, and IgA): Kidney cryostat sections ( $5 \mu \mathrm{m}$ thick) were air-dried and fixed in acetone for $10 \mathrm{~min}$. The sections were washed with phosphate buffered saline (PBS), pH 7.3 and incubated with PBS containing $10 \%$ normal goat sera to block non-specific binding sites. Indirect immunofluorescence techniques were applied using a panel of antibodies cross-reactive with gerbils immu- 
noglobulins, directed against IgG (rabbit antibody to rat IgG $(\mathrm{H}+\mathrm{L})$ (Chemicon International Inc., Temecula, CA, USA); IgM (goat F(ab') 2 fragment to mouse IgM) (American Qualex, La Mirada, CA, USA), rabbit IgG to goat IgG $(\mathrm{H}+\mathrm{L})$ (Wako Pure Chemical Industries, Ltd., Osaka, Japan) and IgA (rabbit antibody to mouse IgA) (ZYMED Laboratories, Inc., San Francisco, CA, USA). Antibodies were applied in a working dilution 1:100 as first layers. FITC-conjugated affinity purified goat antirabbit IgG (E.Y Laboratories, Inc., San Mateo, CA, USA) were used as second layer in a working dilution 1:200. For control sections the primary antibody was omitted to assess non-specific staining. Kidney cryostat sections from normal gerbils were used as negative control.

b) Immunohistochemical staining for visualization of gerbil T-cells: Cryostat sections were air dried and fixed in cold acetone for $10 \mathrm{~min}$. The immunohistochemical staining was performed using a novel mouse monoclonal antibody (HUSM-M.g.15 of IgG2b isotype) specific to gerbil T-cells (Sato et al., 2000). Undiluted culture supernatant was applied as first layer. Peroxidase conjugated goat $\mathrm{F}\left(\mathrm{ab}^{\prime}\right)_{2}$ fragment to mouse IgG (Fc) (Organon Teknika Corp., Durham, NC, USA) was used as a second layer in a working dilution of 1:200. Bound antibody was detected using color development by 3, 3'-diaminobenzidine, followed by light counter staining with hematoxylin. Intraglomerular and interstitial T-cells infiltration were estimated in 30 glomerular cross-section (gcs) and 50 high power fields (HPF) for each animal, respectively.

\section{STATISTICAL ANALYSIS}

S tatistical significance of the results was determined using Student's $t$-test. Data were expressed as mean \pm SD and a $P$ value of less than 0.05 was taken as the minimum level of significance.

\section{RESULTS}

G erbils showed glomerulonephritis, $17 \%(25 / 144)$ of the total infected, earliest at $20 \mathrm{wk}$ post infection (p.i). However, the prevalence of such glomerulonephritis became more than $80 \%$ in the group infected with 50 cercariae or more at $30 \mathrm{wk}$ p.i (Fig. 1A). In this study animals were defined positive when over $40 \%$ of the glomeruli present in three nonconsecutive kidney sections showed histological and immunopathological lesions. Fifty cercariae were the optimum dose to produce glomerulonephritis without early death of the animals. It was confirmed by repeated experiment for its reproducibility (unpublished data). Groups infected with a higher dose of cercariae showed a higher prevalence of glomerulonephritis but a shorter period of survival (Fig. 1A, B). None of the control animals revealed any glomerulonephritis.

Gerbils infected with 50 cercariae showed gradual and consistent elevations of serum creatinine level (Fig. 2A). However, their serum cholesterol and BUN (Fig. 2B) levels were mild and irregular, did not correlate well with the intensity and duration of infection. The increase in total proteins was considerably greater in those infected gerbils while proportional decrease in serum albumin levels was observed in these animals, but the absolute amount of serum albumin did not diminish (Fig. 3A, B).

Mean glomerular diameters gradually increased in the infected groups and became significantly different from those of controls at $20 \mathrm{wk}$ p.i (Table I). Glomerular cell counts gradually increased in all the infected gerbils. The increased cellularity became significant from $20 \mathrm{wk}$ p.i in all the groups infected with 50 cercariae and more (Table II). Glomerular hypercellularity was due to infiltration of inflammatory cells and endocapillary cellular
Fig. 1. - Effect of intensity and duration of infection with Schistosoma mansoni cercariae on the prevalence of glomerulonephritis (A) and survival rate of gerbils (B). Gr-1: 0 cercaria (O); Gr-2: 25 cercariae (D); Gr-3: 50 cercariae $(\Delta)$; Gr-4: 100 cercariae $(\Delta)$ and Gr-5: 150 cercariae infection ( $\mathbf{\square}$ ). The number of gerbils at the beginning of the experiment was six at each time points.
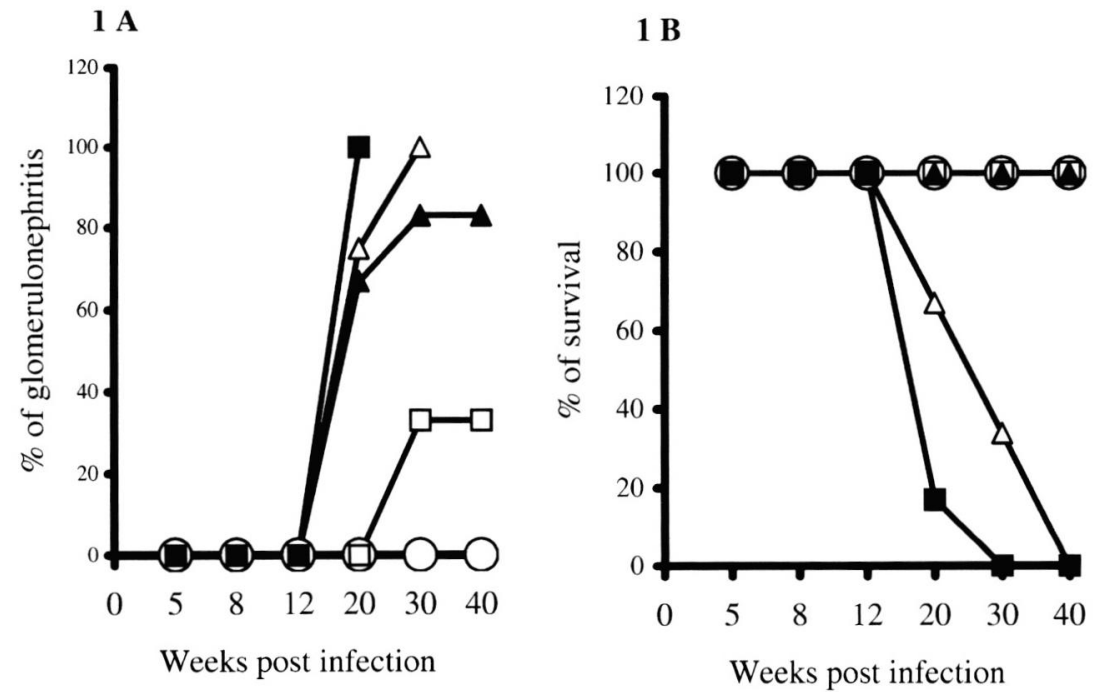
proliferations. Infiltrated cells were mostly mononuclear cells (MNC) and a few neutrophils. Immunohistochemistry using HUSM-M.g.15 specific to gerbil T-cells revealed that more than $50 \%$ of the infiltrated MNC were T-cells. Intraglomerular and interstitial infiltration of T-cells were significantly different from the controls (Fig. 4A, B). Immunofluorescence staining showed negative for immune complex deposition.
Heterogeneous types of glomerular lesions, membranoproliferative (Fig. 5B), focal segmental to diffuse proliferative (Fig. 5C) and necrotizing glomerulonephritis (Fig. 5D) were observed. Glomerular sclerosis (Fig. 5E, F) along with tubular atrophy, dilatation, necrosis, and interstitial infiltration of inflammatory cells were also observed. Sclerosed glomeruli were seen adjacent to apparently normal glomeruli (Fig. 5A). Sclerosed areas
2 A

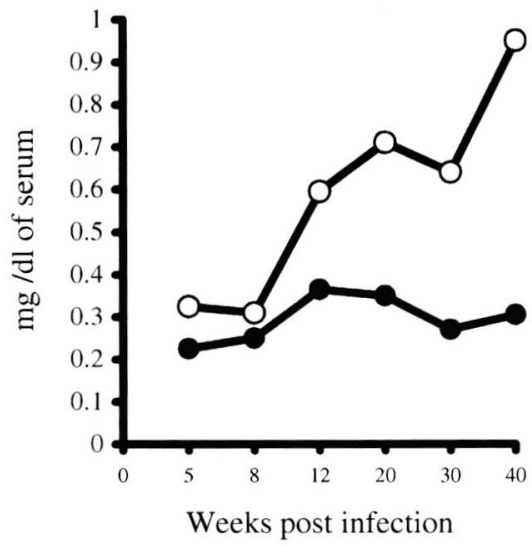

$3 \mathrm{~A}$

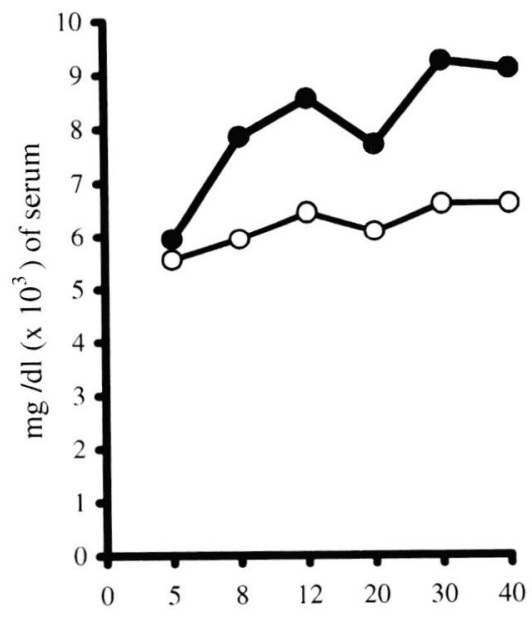

2 B

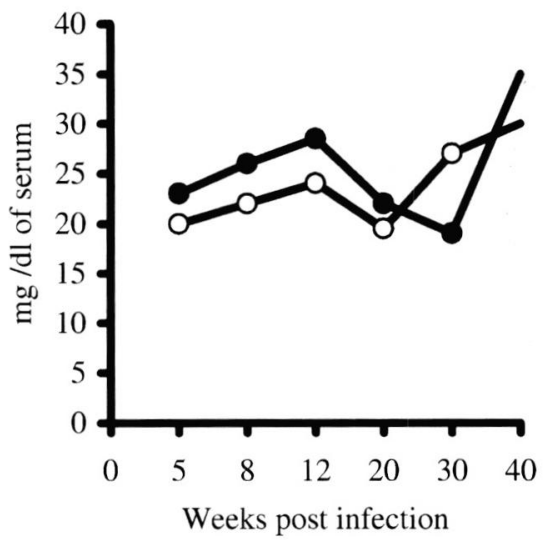

3 B

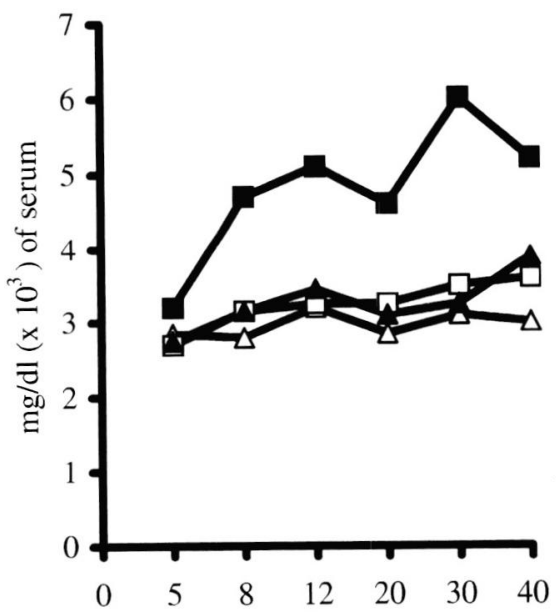

Fig. 2. - Kinetics of serum creatinine (A) and blood urea nitrogen (BUN) levels (B) in the gerbils infected with 50 cercariae of $S$. mansoni. Each time points represent pooled sera of six control $(-)$ or infected $(O)$ gerbils.
Fig. 3. - Kinetics of serum total proteins (A) and its albumin and globulin (B) in the gerbils exposed to 50 cercariae of $S$. mansoni. Each time points represent total protein of control $(\bigcirc)$, infected $(\mathbf{)})$ gerbils, albumin of control $(\Delta)$, albumin of infected $(\boldsymbol{\Delta})$, globulin of control (a), globulin of infected ( $\mathbf{a})$ animals, estimated from pooled sera of six gerbils.

\begin{tabular}{|c|c|c|c|c|c|c|}
\hline \multirow{2}{*}{$\begin{array}{c}\text { No. } \\
\text { of cercariae } \\
\text { infected }\end{array}$} & \multicolumn{6}{|c|}{ Glomerular diameter $(\mu \mathrm{m})$ at different weeks p.i. } \\
\hline & $5 \mathrm{wk}$ & $8 \mathrm{wk}$ & $12 \mathrm{wk}$ & $20 \mathrm{wk}$ & $30 \mathrm{wk}$ & $40 \mathrm{wk}$ \\
\hline 0 & $69 \pm 2$ & $71 \pm 3$ & $75 \pm 3$ & $72 \pm 6$ & $77 \pm 5$ & $75 \pm 3$ \\
\hline 25 & $73 \pm 8$ & $73 \pm 8$ & $80 \pm 5$ & $78 \pm 5$ & $85 \pm 5^{*}$ & $82 \pm 5^{* * *}$ \\
\hline 50 & $75 \pm 8$ & $77 \pm 6$ & $78 \pm 4$ & $79 \pm 3^{*}$ & $93 \pm 5^{* * *}$ & $91 \pm 6^{* * *}$ \\
\hline 100 & $74 \pm 6$ & $76 \pm 4$ & $80 \pm 5$ & $91 \pm 1^{\mathrm{a} * * *}$ & $96 \pm 6^{\mathrm{b} * *}$ & NA \\
\hline 150 & $75 \pm 6$ & $77 \pm 5$ & $80 \pm 6$ & $94^{c}$ & NA & NA \\
\hline
\end{tabular}

Each point represents mean \pm SD. Total 30 glomeruli/animal were measured by means of an ocular micrometer. The values were evaluated by Student's $t$-test and found significant, where $P<0.05$, comparing with control ( 0 cercariae). NA: Animal not available for examination. Six gerbils at each group except three groups, where ${ }^{\mathrm{a}}: 4 ;{ }^{b}: 2$ and ${ }^{c}: 1$ gerbil. ${ }^{*}: P<0.05 ;{ }^{* *}: P<0.01 ;{ }^{* * *}: P<0.001$.

Table 1. - Mean glomerular diameter of gebils infected with different number of Schistosoma mansoni cercariae at different weeks p.i. 


\begin{tabular}{|c|c|c|c|c|c|c|}
\hline \multirow{2}{*}{$\begin{array}{c}\text { No. } \\
\text { of cercariae } \\
\text { infected }\end{array}$} & \multicolumn{6}{|c|}{ No. of cells/glomerulus at different weeks p.i. } \\
\hline & $5 \mathrm{wk}$ & $8 \mathrm{wk}$ & $12 \mathrm{wk}$ & $20 \mathrm{wk}$ & $30 \mathrm{wk}$ & $40 \mathrm{wk}$ \\
\hline 0 & $34 \pm 1$ & $33 \pm 4$ & $34 \pm 5$ & $33 \pm 3$ & $32 \pm 2$ & $36 \pm 3$ \\
\hline 25 & $37 \pm 5$ & $38 \pm 6$ & $37 \pm 3$ & $38 \pm 8$ & $49 \pm 4^{* * *}$ & $57 \pm 7^{* * *}$ \\
\hline 50 & $36 \pm 4$ & $40 \pm 8$ & $40 \pm 6$ & $44 \pm 5^{* * *}$ & $54 \pm 5^{* * *}$ & $72 \pm 9^{* * *}$ \\
\hline 100 & $34 \pm 3$ & $39 \pm 8$ & $41 \pm 6$ & $47 \pm 6^{a * *}$ & $53 \pm 2^{\mathrm{b} * * *}$ & NA \\
\hline 150 & $35 \pm 3$ & $40 \pm 8$ & $40 \pm 5$ & $54^{c}$ & NA & NA \\
\hline
\end{tabular}

Each point represents no. of cells/glomerular cross-section (mean \pm SD). Total 30 glomeruli/animal were examined and their contained cells were counted using high power objectives. Cellularity was evaluated by Student's $t$-test and found significant, where $P<0.05$, comparing with the control $\left(0\right.$ cercariae). NA: Animal not available for examination. Six gerbils, at each group except three, where ${ }^{a}: 4 ;{ }^{b}: 2$ and c: 1 gerbil. ${ }^{* *}: P<0.01 ;{ }^{* * *}: P<0.001$.

Table II. - Glomerular cellularity of gerbils infected with different number of Schistosoma mansoni cercariae at different weeks p.i.

$4 \mathrm{~A}$

Fig. 4. - T-cell infiltration, intraglomerular (A) and interstitial (B), in gerbils infected with S. mansoni at 30 -wk p.i. Gr-1: Control, $\mathrm{n}=6$; Gr-2: infected with 25 cercariae, $\mathrm{n}=6$; Gr-3: infected with 50 cercariae, $n=6$ and Gr-4: infected with 100 cercariae, $\mathrm{n}=2$. (A) No. of $\mathrm{T}$ cells/glomerular cross-section (c/gcs), total 30 glomeruli/animal were examined; (B) interstitial infiltration of T-cells/50 HPF. The values were evaluated by $t$-test and found significant, where $P<$ 0.05 , comparing with control group. *: $P<0.05 ;{ }^{* *}: P<0.01$; ***: $P<0.001$.

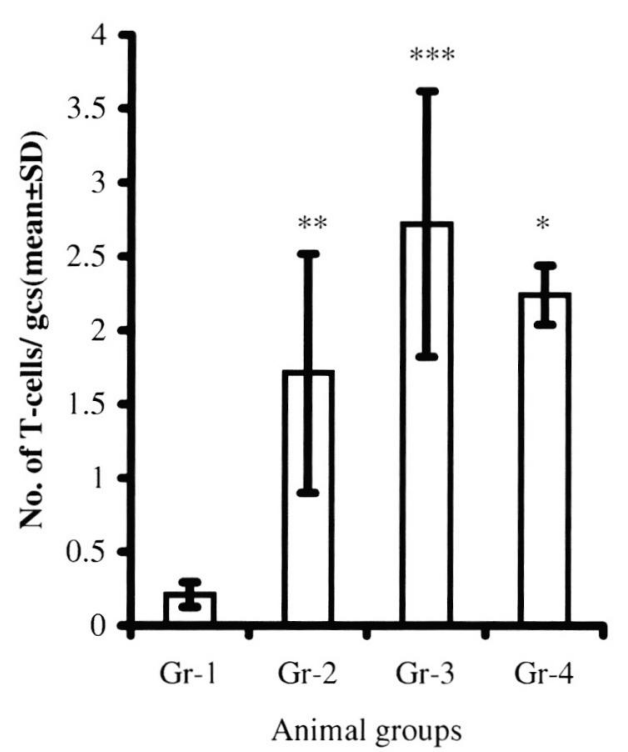

$4 B$

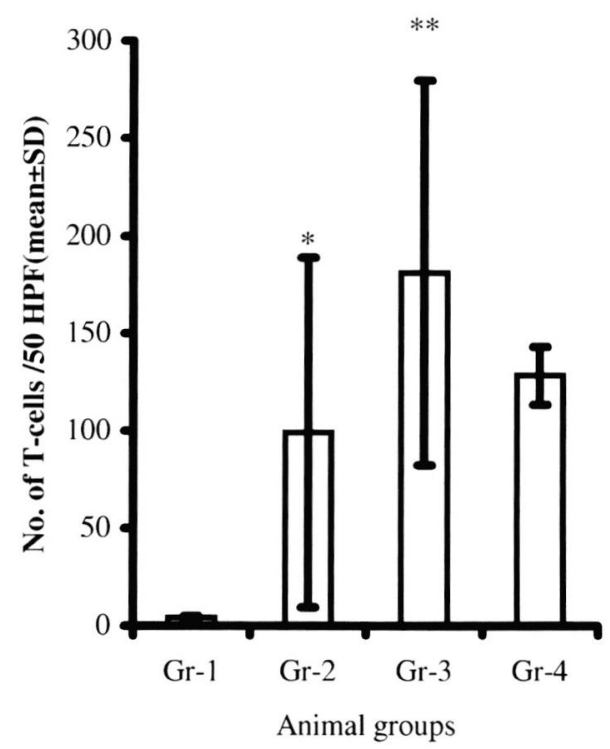

assumed hyaline like appearance in $\mathrm{H} / \mathrm{E}$, which was PAS and PASM positive. Some of the tubules showed cellular and hyaline cast. Accumulations of MNCs in and around some of the altered glomeruli (Fig. 5E) were observed. TEM revealed renal abnormalities earliest at $20 \mathrm{wk}$ p.i in the 50 cercariea and more infected gerbils. The abnormalities were wrinkling and irregular thickening of the glomerular basement membrane (GBM) with variable degree of severity (Fig. 6A, B), increased mesangial area and cellularity (Fig. 6C) in more than $40 \%$ of the infected gerbils. Peritubular accumulation of MNCs and tubular basement membrane (TBM) abnormalities were also observed (Fig. 6D). Out of 144 infected gerbils only two showed granuloma with renal egg deposition. Five $(3.5 \%)$ of the infected gerbils exhibited amyloid deposition earliest at $30 \mathrm{wk}$ p.i in the renal glomeruli and interstitium. Electron microscopy showed that the glomerular amyloid deposits were mainly subendothelial (Fig. 6E, F). None of the control gerbils showed any amyloid deposits.

\section{DISCUSSION}

chistosomal glomerulonephritis is considered a $\circlearrowleft$ late complication of hepatosplenic schistosomiasis with collateral circulation, where eggs bypass the hepatic filter and are carried to the lungs and then to the systemic circulation (Andrade et al., 1971). This will permit the diversion of the immune complex (IC) away from the liver and its Kupffer' cells. Thus the complexes will reach the kidney and other organs by the systemic circulation.

In our present study, 50 cercariae were the optimum dose of infection at which majority of gerbils showed glomerulonephritis (Fig. 1A) at 30-wk p.i. This dose was well tolerated up to 40-wk p.i and glomerular changes were almost similar to higher dose groups. None of the control animals showed any glomerulonephritis. The serum biochemical findings in infected gerbils contrasted in some important respects (cholesterol and BUN) with the biochemical observations 


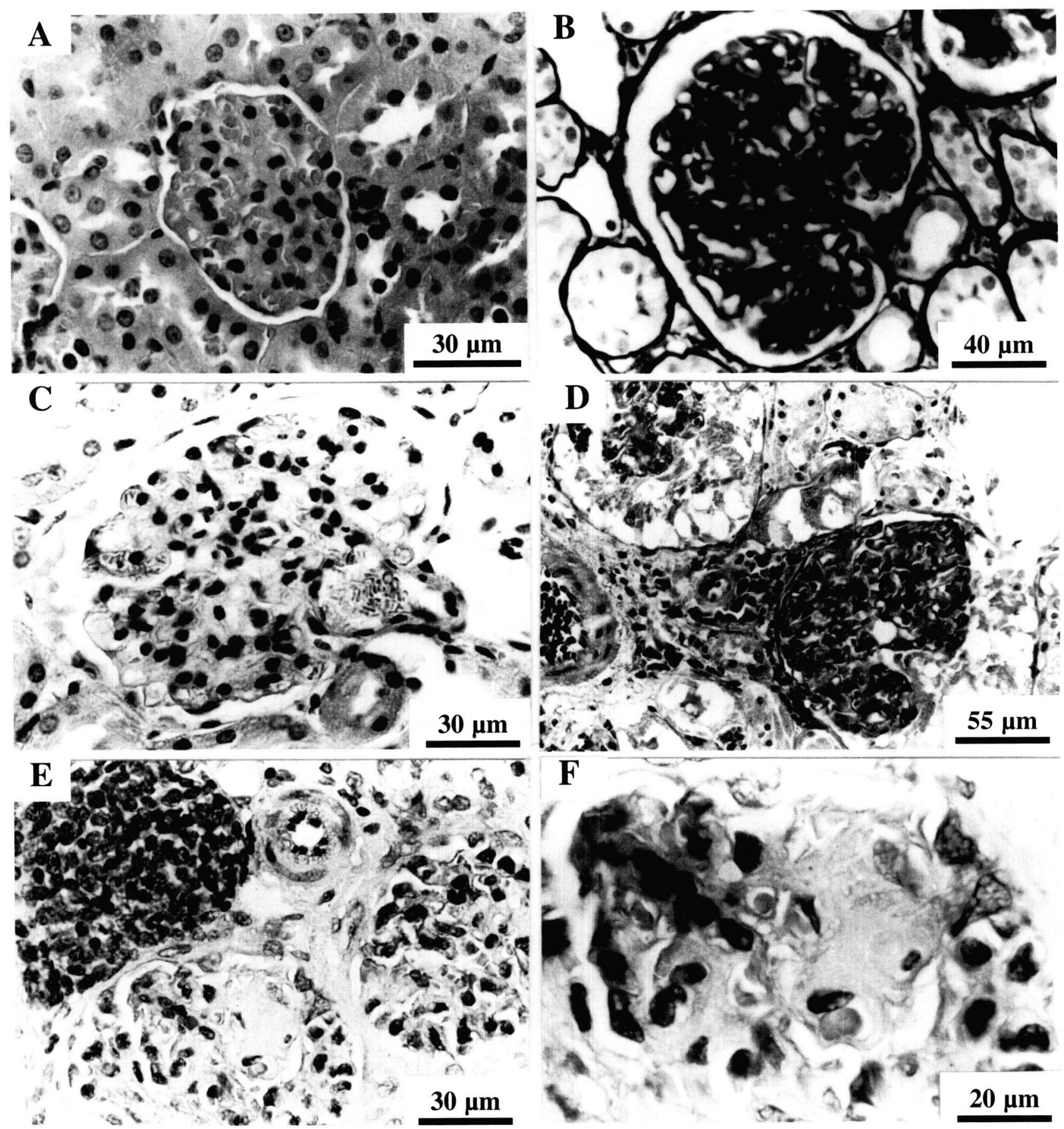

Fig. 5. - Pathological changes in the kidney of gerbils exposed to 50 cercariae at $30 \mathrm{wk}$ p.i. (A) morphologically normal (control, H/E); (B) mesangioproliferative GN (PASM); (C) proliferative GN (H/E); (D) necrotizing GN (H/E); (E) Segmental glomerulosclerosis with periglomerular and interstitial mononuclear cells infiltration $(\mathrm{H} / \mathrm{E})$; (F) Glomerulosclerosis where sclerosing capillary loops assumed hyaline appearance $(\mathrm{H} / \mathrm{E})$. 


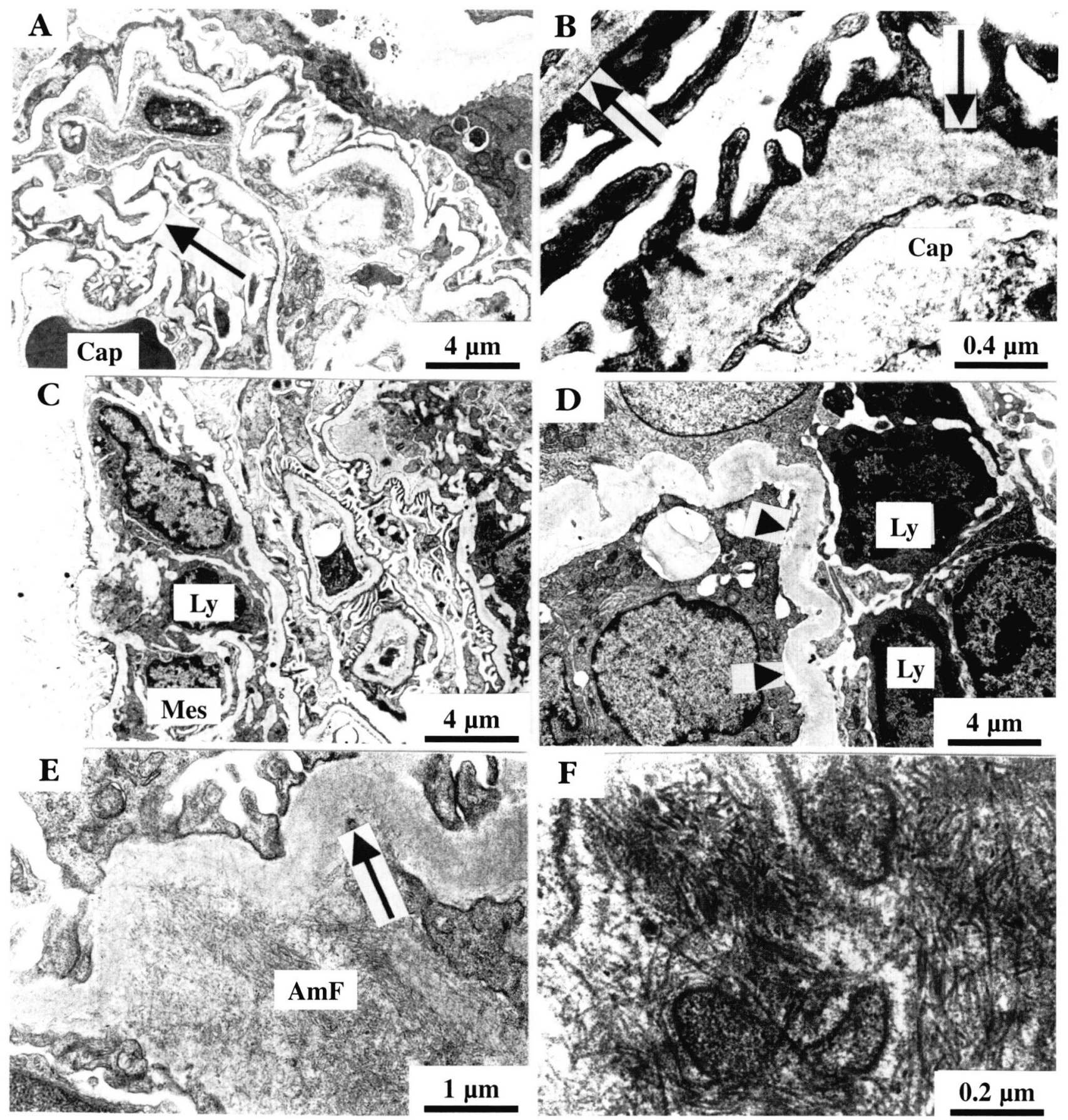

Fig. 6. - Electron micrograph of a glomerulus of gerbils exposed to 50 cercariae of $S$. mansoni is showing wrinkling and irregular thickening of the glomerular basement membrane (A \& B) with increased no. of cells in the mesangial area (C), along with alteration of tubular basement membrane (D) at 30 wk p.i., subendothelial amyloid deposition (E) with randomly oriented fibrils of higher magnification (F) at $40 \mathrm{wk}$ p.i. Note: arrow, indicate glomerular basement membrane; arrow head, tubular basement membrane; Mes, mesangial cell; Cap, capillary lumen; Ly, lymphocyte; AmF, amyloid fibril. 
reported for mice with schistosomiasis (Sadun \& Williams, 1966). On the other hand, the significant and consistent increases in creatinine, total protein and globulin concentration recorded in hamsters (Sobh et al., 1991), mice (Sadun \& Williams, 1966) and chimpanzees (Sadun et al., 1970) were also observed in infected gerbils. The increase in globulin concentration in the absence of corresponding increases in albumin produced striking reduced albumin: globulin ratio. These were more evident in the animals with heavier infections and became more marked with time (Sobh et al. 1991; Sadun et al., 1970).

Heterogeneous types of glomerular lesions (Fig. 5) along with tubulo-interstitial changes were observed in gerbils. Similar morphological changes were also observed in humans (Cheever, 1968; Andrade et al., 1971; Sobh et al., 1989) and other animals (Sadun et al., 1975; Sobh et al., 1991). Several investigators demonstrated mesangial hypercellularity accompanied by IgG glomerular deposits (Sobh et al., 1991; Hilleyer \& Lewert, 1974) without abnormality of the GBM (Hilleyer \& Lewert, 1974) in hamsters. Mesangial hypercellularity was seen in our experiment but did not affect all the glomeruli of the infected gerbils. However, wrinkling and irregular thickening of the GBM were observed in more than $40 \%$ of the infected gerbils. But the mechanism of these pathological changes remained unknown. It cannot be explain by renal egg deposition since renal egg depositions were sporadic (2/144) but glomerular lesions were much more prevalent.

Amyloidosis may be one of the pathogenetic mechanisms of schistosomal glomerulonephritis, where $3.5 \%$ of the infected gerbils revealed amyloidosis (Fig. 6E, F). None of the control gerbils showed any amyloid deposits. Amyloidosis secondary to schistosomal infections has also been reported in $8 \%$ infected hamsters (Sobh et al., 1991) and $16 \%$ of humans schistosomiasis (Barsoum et al., 1979).

In schistosomiasis, IC mediated glomerulonephritis have been reported in mice (Natali \& Cioli, 1976; Fujiwara et al., 1988), hamsters (Sobh et al., 1991), monkeys (Tada et al., 1975) and humans (Sobh et al., 1987). Recently immunoelectron microscopic localization of schistosomal antigen in the glomerulus of hamsters, where mesangial expansion with increased cellularity has been reported (De Brito et al., 1998). It is interesting to note here that GBM, tubules and interstitium were unremarkable in hamsters but in our study, infiltration of MNCs with irregular thickening of the GBM were observed. In our gerbil model the glomerular lesions are most probably not IC mediated, since IF staining and TEM of kidney tissues did not reveal the deposition of IC in the mesangium and capillary walls. In humans IC negative GN with increased number of MNCs in the glomeruli has been reported and subtyping of these MNCs in kidney showed significant increases (0.5 2 c/gcs) of T-cells (Nolasco et al., 1987; Tipping et al., 1985). There is now evidence that Tcells play a major role in glomerular injury, where $\mathrm{CD}^{+}$ T-cells responsible for the induction of autoimmune syndrome and glomerular infiltrations of $\mathrm{CD}^{+} \mathrm{T}$-cells are directly involved in the onset of proteinuria (Van Velthuysen, 1996). Glomerular hypercellularity, due to influx of $\mathrm{CD}^{+} \mathrm{T}$-cells, was reported in murine malaria (Lloyd et al., 1993).

Significant T-cells infiltrations in and around some of the altered glomeruli were observed in our study (Fig. 4A, B). These infiltrated T-cells were unable to be clarified due to lack of information on T-cell subset of gerbils. This abnormal infiltration of T-cells and macrophages in the glomeruli may indicate participation of cellular immunity (Bolton et al., 1987; Saito \& Atkins, 1990; Hooke et al., 1987), although some defects in the macrophage activation system and also in complement have been reported in gerbils (Nasaree et al., 1998; Kamiya et al., 1980). This is in agreement with our previous experiment, where we found lymphocytic myocarditis in gerbils infected with S. mansoni (Chisty et al., 1999). To elucidate the role of Tcells in glomerular injury associated with parasitic infections further studies are suggestive.

\section{ACKNOWLEDGEMENTS}

T This work was supported in part by grants from the Japan Society for the promotion of Science, from Japan-US Medical Cooperative Program and from Sasakawa Health Science Foundation.

\section{REFERENCES}

ANDRAdE Z.A. \& Rocha H. Schistosomal glomerulopathy. Kidney International, 1979, 16, 23-29.

ANDRADE Z.A. \& Susin M. Renal changes in mice infected with Schistosoma mansoni. American Journal of Tropical Medicine E Hygiene, 1974, 23, 400-402.

Andrade Z.A., Andrade S.G. \& Sadigursky M. Renal changes in patients with hepatosplenic schistosomiasis. American Journal of Tropical Medicine E Hygiene, 1971, 20, 77-83.

BARSOUm R.S. Schistosomal glomerulopathies. Kidney International, 1993, 44, 1-12.

Barsoum R.S., Bassily S., Soliman M.M., Ramzy M.F., Milad M. \& Hassballa A.M. Renal amyloidosis and schistosomiasis. Transactions of The Royal Society of Tropical Medicine $\&$ Hygiene, 1979, 73, 367-374.

Bolton W.K., Innes D.J., Sturgill B.C. \& Kaiser D.L. T-cells and macrophages in rapidly progressive glomerulonephritis: clinicopathological correlation. Kidney International, 1987, 32, 869-876. 
Brack M., Mcphaul J.J., Damian R.T. \& Kalter S.S. Glomerular lesions in normal and Schistosoma mansoni infected baboons (Papio cynocephalus). Journal of Medical Primatology, 1972, 1, 363-373.

Cheever A.W. A quantitative post mortem studies of Schistosomiasis mansoni in man. American Journal of Tropical Medicine \& Hygiene, 1968, 17, 38-50.

Chisty M.M., Nargis M., Sato H., Inaba T. \& Kamiya H. Occurrence of myocarditis in rodents infected with Schistosoma mansoni. Southeast Asian Journal of Tropical Medicine E Public Health, 1999, 33, 556-561.

De Brito T., Carneiro C.R.W., Nakhle M.C., Lima D.M.C., Lemos C.P.A., SANDOval M. \& Silva A.M. Localization of immunoelectron microscopy of Schistosoma mansoni antigens in the glomerulus of hamster (Mesocricetus auratus) kidney. Experimental Nephrology, 1998, 6, 368-376.

De Brito T., Gunji J., Camargo H.E., Ceravolo A. \& De Silva L.C. Glomerular lesions in experimental infections of Schistosoma mansoni in cebus apella monkey. Bulletin World Health Organization, 1971, 45, 419-422.

Fujiwara M., Makino M. \& Watanabe H. Schistosoma mansoni: induction of severe glomerulonephritis in female BXSB mice following chronic infection. Experimental Parasitology, 1988, 65, 214-221.

Hillyer G.V. \& LEWERT R.M. Studies on renal pathology in hamsters infected with Schistosoma mansoni and S. japonicum. American Journal of Tropical Medicine \& Hygiene, 1974, 23, 404-411.

Hooke D.H., Gee D.C. \& Atkins R.C. Leukocyte analysis using monoclonal antibodies in human glomerulonephritis. Kidney International, 1987, 31, 964-972.

Hoshino-Shimizu S., De Brito T., Kanamura H., Canto A.L., Silva A.Q., Campos A.R., Penna D.O. \& Silva L.C. Human schistosomiasis: S. mansoni antigen detection in renal glomeruli. Transactions of The Royal Society of Tropical Medicine and Hygiene, 1976, 70, 492-496.

Kamiya H., Kamiya M. \& Ohbayashi M. Studies on the host resistance to infection with Echinococcus multilocularis: 2. Lytic effect of complement and its mechanism. Japanese Journal of Parasitology, 1980, 29, 169-179.

Lloyd C.M., Wozencraft A.O. \& William D.G. Cell-mediated pathology during murine malaria-associated nephritis. Clinical and Experimental Immunology, 1993, 94, 398-402.

Nasarre C., KRahenbuhl J.H. \& KleI T.R. Down regulation of macrophage activation in Brugia pahangi-infected jirds (Meriones unguiculatus). Infection and Immunity, 1998, 66, 1063-1069.

Natali P.G. \& CiOli D. Immune complex nephritis in Schistosoma mansoni infected mice. European Journal of Immunology, 1976, 6, 359-364.

Nolasco F.E.B., Cameron J.S., Hartley B., Coelho A., HilDRETH G. \& REUBEN R. Intraglomerular T cells and monocytes in nephritis: study with monoclonal antibodies. Kidney International, 1987, 31, 1160-1166.

Robinson A., Lewert R.M. \& SPARgo B.H. Immune complex glomerulonephritis and amyloidosis in Schistosoma japonicum infected rabbits. Transactions of The Royal Society of Tropical Medicine and Hygiene, 1982, 76, 214-226.
Rocha H., Cruz T., Brito E. \& Susin M. Renal involvement in patients with hepatosplenic schistosomiasis mansoni. American Journal of Tropical Medicine E Hygiene, 1976, 25, 108-114.

Sadun E.H., Reid W.A., Cheever A.W., Duvall R.H., Swan K.G., Kent K.M., Bruce J.I. \& Lichtenberg F.V. Effect of portocaval shunting on Schistosoma japonicum infection in chimpanzees: dissociation of pipe stem fibrosis and glomerulopathy. American Journal of Tropical Medicine $E$ Hygiene, 1975, 24, 619-631.

Sadun E.H., Von lichtenberg F., Cheever A.W. \& Erickson D.G. Schistosomiasis mansoni in the chimpanzee. The natural history of chronic infections after single and multiple exposures. American Journal of Tropical Medicine E Hygiene, 1970, 19, 258-277

SADUN E.H. \& Williams J.S. Biochemical aspects of Schistosoma mansoni in mice in relation to worm burdens and duration of infection. Experimental Parasitology, 1966, 18, 266-273.

SAITO T. \& ATKInS R.C. Contribution of mononuclear leukocytes to the progression of experimental focal glomerular sclerosis. Kidney Internatioinal, 1990, 37, 1076-1083.

Sato H., Ihama Y. \& KamiYa H. Survival of destrobilated adults of Taenia crassiceps in T-cell depleted Mongolian gerbils. Parasitology Research, 2000, 86, 284-289.

Sobh M., Moustafa F., Ramzy R., SaAd M., Deelder A. \& GHONEIM M. Schistosoma mansoni nephropathy in Syrian golden hamsters: effect of dose and duration of infection. Nephron, 1991, 59, 121-130.

Sobh M.A., Moustafa F.F., Sally S.M., Foda M.A.M., Deelder A.M. \& GHONeim M.A. A prospective, randomized therapeutic trial for schistosomal specific nephropathy. Kidney International, 1989, 36, 904-907.

Sobh M., Moustafa F., Sally S., Deelder A. \& Ghoneim M. Effect of anti-schistosomal treatment on nephropathy. Nephrology Dialysis Transplantation, 1988, 3, 744-751.

Sobh M., Moustafa F.F., El Housseini F., Basta M.T., Deelder A.M. \& GHONEIM M.A. Schistosomal specific nephropathy leading to end-stage renal failure. Kidney International, 1987, 31, 1006-1011

SMITHERS S.R. \& TERRY R.J. The infections of laboratory hosts with cercariae of Schistosoma mansoni and the recovery of the adult worms. Parasitology, 1965, 55, 695-700.

Tada M.A., Kondo Y.M., OKumura K., Sano M. \& YoKoGAWA M. Schistosoma japonicum: immunopathology of nephritis in Macaca fascicularis. Experimental Parasito$\log y, 1975,38,291-302$.

Tipping P.G., Neale T.J. \& Holdsworth S.R. T lymphocyte participation in antibody induced experimental glomerulonephritis. Kidney International, 1985, 27, 530-537.

VAN VELTHUYSEN M.L.F. Glomerulopathy associated with parasitic infections. Parasitology Today, 1996, 12, 102-107.

Yingrui L., YaXian G., Xinyuan Y., Zianfang Z., LongXiang P. \& QINGSHAN Z. Schistosoma japonicum: a comparison of the development of the parasite and associated pathological changes in mice and jirds (Meriones unguiculatus). International Journal of Parasitology, 1983, 13, 531-538.

Reçu le 11 décembre 2000 Accepté le 17 décembre 2001 
